\title{
Comparison the Values of Stresses for the Mode I Stress Intensity Factor for a Double Edge Cracked Tension (Isotropic \& Orthotropic) Plates
}

\author{
Ahmed M. Abdullah \\ Assistant Lecturer / Mech. Eng. Dept./ University of Mosul
}

\begin{abstract}
No one can deny the fact that cracked plates modeling is important to detect structural damage. The strength calculation of different constructions is troubled by various defects, which accelerate the formation of cracks as well as the process of fracture. This research presents a comparison between the results obtained by FEA techniques for isotropic and orthotropic plates, general solutions for model-based approach which represents the cracked plates that subjected to a tensile load for determining the stresses,.. The finite element formulation is carried out in the using analysis section of the "ANSYS 12" package to obtain the stresses and compare the results.
\end{abstract}

Keywords: Finite Element, Cracks Simulation, ANSYS, Plates.

$$
\begin{aligned}
& \text { مقارنة قيم الإجهادات في قطعتين معدنيتين (موحدة وغير موحدة الخواص) ذواتي شق مثق }
\end{aligned}
$$

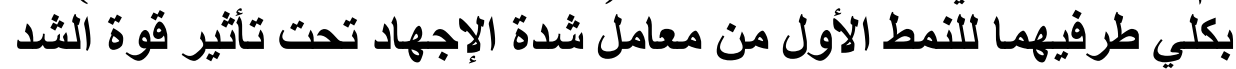

$$
\begin{aligned}
& \text { أحمد محمود عبدالله } \\
& \text { / قسم الهندسة الميكانيكية / جامعة الموصل مدرس مساعد } \\
& \text { الخلاصة }
\end{aligned}
$$

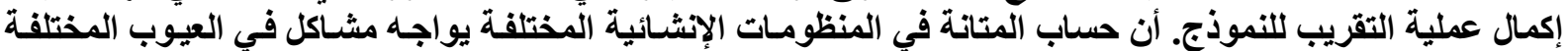

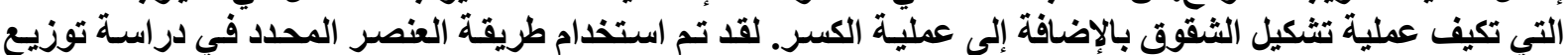

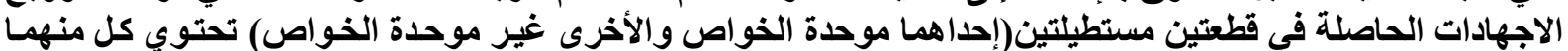

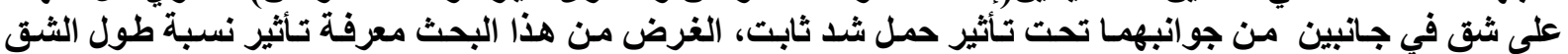

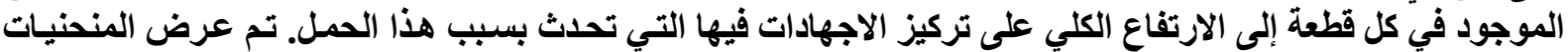

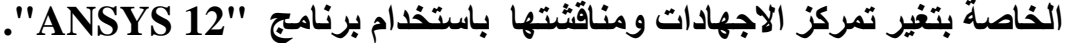
الكلمات المفتاحية: العنصر المحدد ، محاكاة الثقوق ، الانسزئن الصفائح. 


\section{Nomenclature}

\begin{tabular}{|c|c|c|}
\hline Symbol & Definition & Unit \\
\hline$\lambda$ & Normalized crack length & -- \\
\hline $\mathrm{a}$ & Crack length in each side & $\mathrm{mm}$ \\
\hline $\mathrm{h}$ & Specimen height & $\mathrm{m}$ \\
\hline $\mathrm{T}$ & Tensile load & $\mathrm{N} / \mathrm{m}^{2}$ \\
\hline $\mathrm{Ex}$ & Specimen length & $\mathrm{N} / \mathrm{m}^{2}$ \\
\hline Ey & Modulus of elasticity in X axis & $\mathrm{N} / \mathrm{m}^{2}$ \\
\hline Ez & Modulus of elasticity in Y axis & -- \\
\hline$\mu \mathrm{xy}$ & Modulus of elasticity in Z axis & -- \\
\hline$\mu \mathrm{yz}$ & Poisson's ratio in XY plane & -- \\
\hline$\mu z \mathrm{zx}$ & Poisson's ratio in YZ plane & $\mathrm{N} / \mathrm{m}^{2}$ \\
\hline $\mathrm{Gxy}$ & Poisson's ratio in ZX plane & $\mathrm{N} / \mathrm{m}^{2}$ \\
\hline $\mathrm{Gyz}$ & Modulus of rigidity in XY plane & $\mathrm{N} / \mathrm{m}^{2}$ \\
\hline $\mathrm{GzX}$ & Modulus of rigidity in YZ plane & $\mathrm{N} / \mathrm{m}^{2}$ \\
\hline $\mathrm{KI}$ & Modulus of rigidity in ZX plane & $\mathrm{N} / \mathrm{m}^{2}$ \\
\hline$\sigma_{r r}$ & Stress Intensity Factor & $\mathrm{N} / \mathrm{m}^{2}$ \\
\hline$\sigma_{\theta \theta}$ & Radial stress component & $\mathrm{N} / \mathrm{m}^{2}$ \\
\hline$\sigma \mathrm{x}$ & Hoop stress component & $\mathrm{N} / \mathrm{m}^{2}$ \\
\hline$\sigma \mathrm{y}$ & Stress in X axis & $\mathrm{N} / \mathrm{m}^{2}$ \\
\hline$\sigma \mathrm{xy}$ & Stress in Y axis & $\mathrm{N} / \mathrm{m}^{2}$ \\
\hline$\sigma \mathrm{von}$ & Shear stress in XY plane & \\
\hline & Von Mises stress & \\
\hline
\end{tabular}

\section{Introduction}

One of the most common incipient losses of structural integrity in mechanical structures is the development and propagation of cracks. A crack may propagate from small imperfections on the surface of the body or inside of the material and it is most likely to appear in correspondence of high stress concentration. For example, Fig.1 shows a crack developed in the stiffening plate of a generator casing. Fretting corrosion, in case of shrink fitted connections, may generate cracks, the development of which is also apparently favored by wet and corrosive environments. Thermal stresses and thermal shocks are also responsible for generating high local stress intensity factors, which can cause the starting of a crack and its propagation.[1].

Fatigue is a phenomenon of failure of material under cyclic or long term stress at stress levels well below their ultimate stress and it is the result of the progressive growth of cracks through the material [2]. Mechanical accidents, fatigue, erosion, corrosion, as well as environmental attacks, are issues that can lead to a crack in a mechanical structure. Cracks are indications of an impending mechanical failure.[3]. Massab`o et al. [4]. derived approximate mode I weight functions for orthotropic double cantilever beams with short and long cracks. The study of Massab`o et al. showed a strong dependence of the weight functions and the fracture behavior 
of delaminated beams and plates on the degree of anisotropy of the material, while in composite laminates or layered systems can be very high. In this paper, approximate mode II weight functions was be derived for isotropic and orthotropic double cantilever beams with short and long cracks. Since late 1950s the crack issue and the behavior of structural elements contain one or more cracks have been considered by researchers seriously. The first attempts for finding an analytical solution for stress and displacement fields near the crack tip were performed by Irwin [5,6]. and Williams [7]. In these works an Airy stress function for an infinite thin plate with a through crack has been suggested and a general governing equation for stress state near the crack tip has been derived. Later, some researchers tried to find a solution for this equation. Sedov [8]. presented a general solution for an internal crack in an infinite plate using plane state stress assumption for symmetric (mode I) and antisymmetric (Mode 2) cases. A large number of empirical and numerical formulations have been reported for several continua with different forms of crack under various forms of loading. The most important and useful forms of these formulae has been collected by Tada et al. [9]. Duffield and Willens [10], presented an analytical and experimental investigation of parametric instability for a stiffened rectangular plate. Therefore, the dynamic instability of the plate has already created the way for direct engineering application. Liew and Kamel [11] have studied the stress intensity factors for the cracks, emanating from circular hole in anisotropic media, under arbitrary loading conditions. Numerically simulated to the growth of a blunted crack for different crack geometries and also studied the effect of the crack tip radius and the ratio of the specimen width to the crack length [12]. The effects of the specimen and crack geometries were also considered elsewhere [13-15]. Loehnert and Belytschko [16], investigated the amplification and shielding effect of micro crack on the macro crack.

\section{Objectives Of This Research}

In this work, the stress values of the mode I, stress intensity factor, for a double edge cracked tension isotropic plate having normalized crack lengths of $\lambda=2 \mathrm{a} / \mathrm{h}=0.1$ to 0.3 , are calculated, Fig.(1). The results were compared with the values of the correction factor $F(\lambda)$ calculated for the same plate but for orthotropic material using analysis section of the ANSYS package. This problem is to be considered as plane stress because the state of stress in which the normal stress $\boldsymbol{\sigma}_{\mathrm{z}}$, and the shear stresses $\boldsymbol{\sigma}_{\mathrm{xz}}$ and $\boldsymbol{\sigma}_{\mathrm{yz}}$ directed perpendicular to the $\mathrm{x}-\mathrm{y}$ plane are assumed to be zero.

\section{Modeling Of a Rectangular Plate With Two Cracks}

An elastic plate with a crack of length $2 \mathrm{a}$ in each side of its center subjected to a uniform longitudinal tensile load (T) at one end and clamped at the other end as shown in Fig.(1). Use a FEM analysis of the 2-D elastic center-cracked tension plate illustrated in Fig. (2) and calculate the stress value of mode I (crack-opening mode) stress intensity factor for the center-cracked plate.

\section{Model Description}

Specimen geometry: length $1=500 \mathrm{~mm}$, height $\mathrm{h}=100 \mathrm{~mm}$. Material: mild steel having Young's modulus E $=210 \mathrm{GPa}$ and Poisson's ratio $\mu=0.3$. A crack is crated perpendicular to the loading direction at the center of the plate and has a length of $20 \mathrm{~mm}$. The center-cracked tension plate is assumed to be in the plane strain condition in the present analysis. Boundary conditions of the elastic plate is subjected to a uniform tensile load in the longitudinal direction at the right end, and clamped to a rigid wall at the left end. 

Al-Rafidain Engineering
Vol.21
No. 4

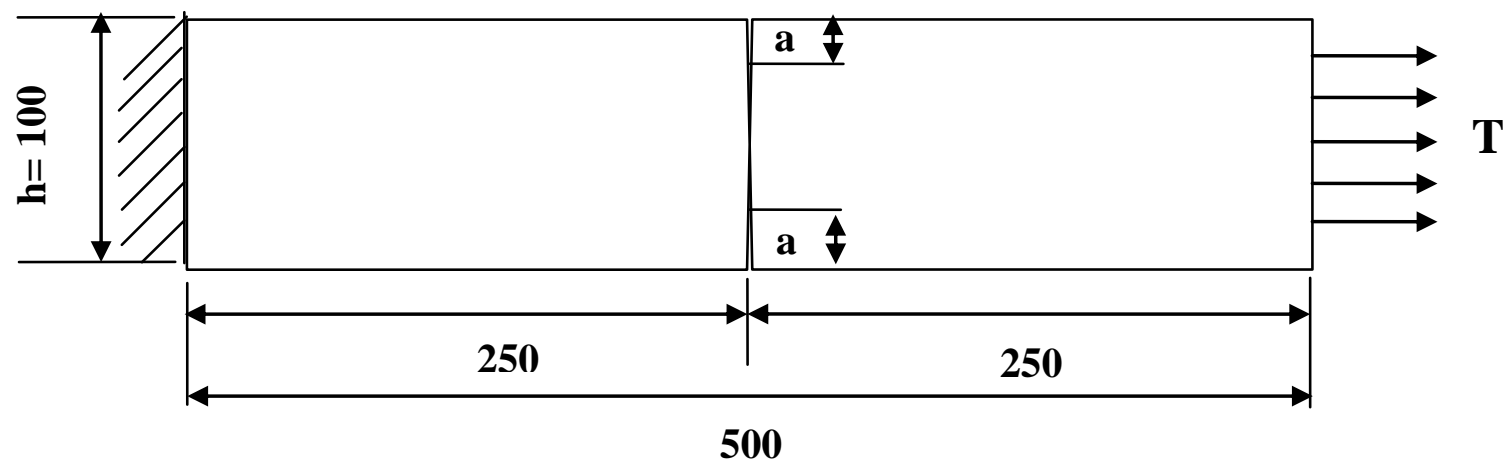

Fig.1 Modeling of a rectangular plate with two cracks.

Table (1): Material properties which used in the analysis.

\begin{tabular}{|c|c|c|}
\hline Properties & Isotropic & Orthotropic \\
\hline $\mathbf{E}_{\mathbf{x}}$ & $225 \mathrm{MPa}$ & $0.216 \mathrm{MPa}$ \\
\hline $\mathbf{E}_{\mathbf{y}}$ & --------------- & $0.13 \mathrm{Mpa}$ \\
\hline $\mathbf{E}_{\mathbf{z}}$ & --------------- & $0.13 \mathrm{MPa}$ \\
\hline $\boldsymbol{\mu}_{\mathbf{x y}}$ & --------------- & 0.3 \\
\hline $\boldsymbol{\mu}_{\mathbf{y z}}$ & ------------ & 0.3 \\
\hline $\boldsymbol{\mu}_{\mathbf{z x}}$ & ------------- & 0.3 \\
\hline $\mathbf{G}_{\mathbf{x y}}$ & $37 \mathrm{KPa}$ & $37 \mathrm{KPa}$ \\
\hline $\mathbf{G}_{\mathbf{y z}}$ & -------------- & $37 \mathrm{KPa}$ \\
\hline $\mathbf{G}_{\mathbf{z x}}$ & ------------- & $37 \mathrm{KPa}$ \\
\hline
\end{tabular}

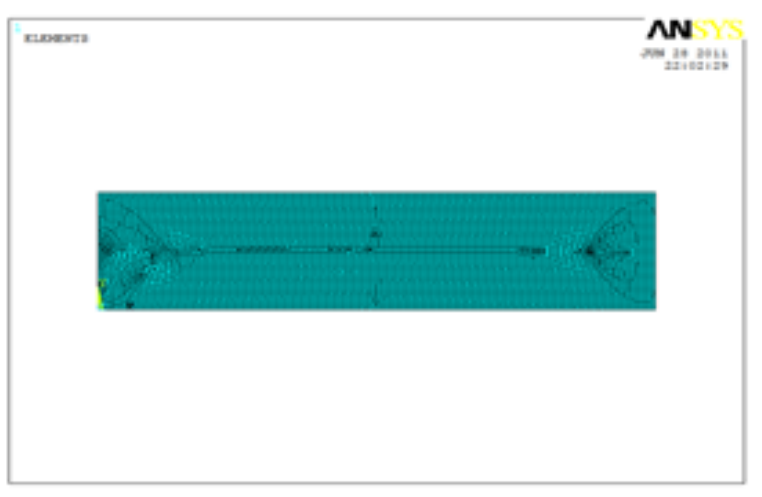

Fig. 2 The finite element model plate area meshed by ordinary 8 -node singular elements

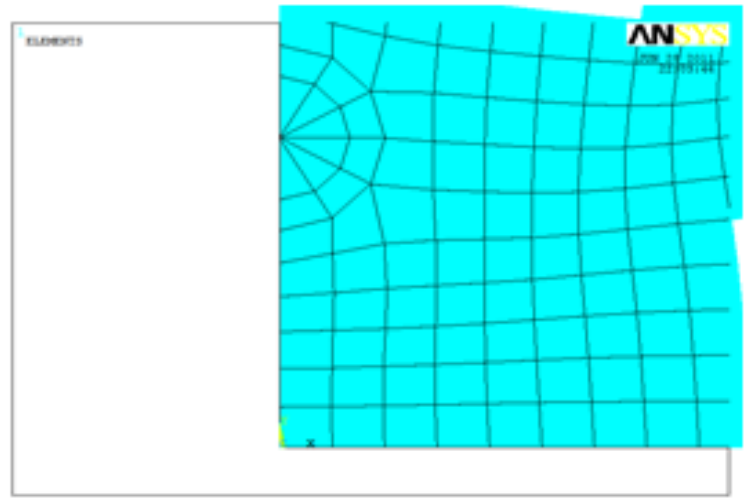

Fig. 3 Enlarged view of the singular elements around the crack tip.

\section{Creation of an Analytical Model}

Let us use a quarter model of the center-cracked tension plate as illustrated in Fig.(1), since the plate is symmetrical about the horizontal and vertical center lines. Here we use the singular element or the quarter point element which can interpolate the stress distribution in the vicinity of the crack tip at which stress has a $1 / \sqrt{ } r$ singularity where $r$ is the distance from the crack tip $(r / a<<1)$. An ordinary isoparametric element which is familiar to "Quad 8node 82" has nodes at the corners and also at the midpoint on each side of the element. A singular element, has a midpoint moved one-quarter side distance from the original midpoint position 
to the node which is placed at the crack tip position. This is the reason why the singular element is often called the quarter point element. (Transition element) ANSYS software is equipped with a 2-D triangular singular element, but neither with 2-D rectangular nor with 3D singular elements are presented. Around the node at the crack tip, a circular area is created and is divided into a designated number of triangular singular elements. Each triangular singular element has its vertex placed at the crack tip position and has a quarter points on the two sides joining the vertex and the other two nodes. In order to create the singular elements, the plate area must be created via key points set at the four corner points and at the crack tip position on the left-end side of the quarter plate area.

\section{Stress Intensity Factor}

A major achievement of the theoretical foundation of LEFM was the introduction of the stress intensity factor $\mathrm{K}$ (the demand) as a parameter for the intensity of stresses close to the crack tip and related to the energy release rate (Bazant and Planas 1998). Ingliss (1913) studied the unexpected failure of naval ships, and Griffith (1921) extended this work using thermodynamic criteria. Using this work, Irwing (1957) developed the concept of the stress intensity factor.

Stress intensity factors are a measure of the change in stress within the vicinity of the crack tip. Therefore, it is important to know the crack direction and when the crack stops propagating. The stress intensity factor is compared with the critical stress intensity factor KIC (the capacity)to determine whether or not the crack will propagate. Dimensional analysis can be used to show that the stress intensity factor for Mode I fracture $K_{\mathrm{I}}$, where $\mathrm{K}_{\mathrm{I}}=\mathrm{g} \sigma \sqrt{\pi a}$ and $\sigma=$ nominal far field stress, $2 \mathrm{a}=$ crack length and $\mathrm{g}$ is a non dimensional function depending on the size and geometry of the crack, size and geometry of the structural component, and the type of loading. For normal cracks, its value ranges between 1 and 2, but it may be larger for longer cracks.Functions defined for common geometries and loading conditions are available in Barsom and Rolfe (1987) and Tada (1973). If $K_{I}$ is the same for two cracked bodies, then based on the equations, the same stress field will exist at their crack tips. If the two bodies are made of the same material, an identical response is expected. This fact leads to the important conclusion that $\mathrm{K}_{\mathrm{I}}$ can be used as a similitude parameter to compare the response of the same material at the crack tip and also to compare the degree at which the materials are

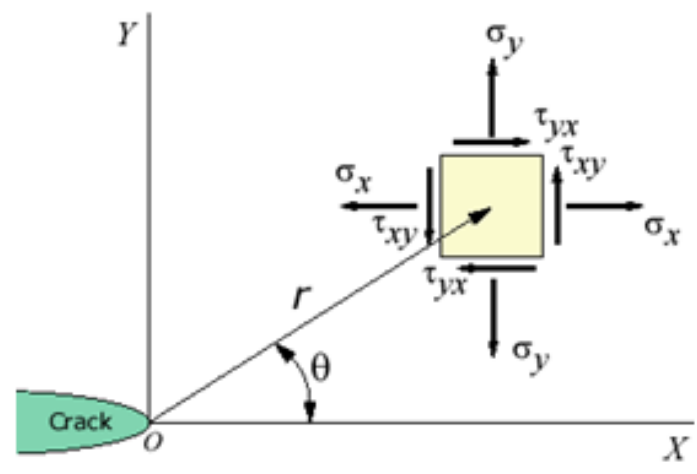

Fig. 4 The crack tip stresses influenced by the stress fields.

\section{Stress Intensity Factor and Crack Tip Stresses}

Crack tips produce a $1 / \sqrt{r}$ singularity. The stress fields near a crack tip of an isotropic linear elastic material can be expressed as a product of $1 / \sqrt{r}$ and a function of $\theta$ with a scaling factor $\mathrm{K}$ : 


$$
\begin{aligned}
& \lim _{\gamma \rightarrow 0} \sigma_{i j}^{(I)}=\frac{K_{I}}{\sqrt{2 \pi r}} f_{i j}^{(I)}(\theta) \\
& \lim _{\gamma \rightarrow 0} \sigma_{i j}^{(I)}=\frac{K_{I I}}{\sqrt{2 \pi r}} f_{i j}^{(I)}(\theta) \\
& \lim _{\gamma \rightarrow 0} \sigma_{i j}^{(I I)}=\frac{K_{I I}}{\sqrt{2 \pi r}} f_{i j}^{(I I)}(\theta)
\end{aligned}
$$

where the superscripts and subscripts I, II, and III denote the three different modes that different loadings may be applied to a crack. The factor $\mathrm{K}$ is called the Stress Intensity Factor. Mode I (Tension, Opening).

The stress distribution around a crack touching the interface can be found e.g. in [17]. Stress-free crack faces require the following boundary conditions:

$$
\sigma_{1 \theta \theta}(r, \pi)=\sigma_{3 \theta \theta}(r,-\pi)=\sigma_{1 r \theta}(r, \pi)=\sigma_{3 r \theta}(r,-\pi)=0
$$

where the subscript 1, 3 indicates region 1 and 3, in Fig. 1. Continuity conditions at the interface lead to the following eight equations for displacements and stress components:

$$
\begin{array}{cc}
u_{1 r}(r, \phi)=u_{2 r}(r, \phi) & u_{3 r}(r, \phi-\pi)=u_{2 r}(r, \phi-r) \\
u_{1 \theta}(r, \phi)=u_{2 \theta}(r, \phi) & u_{3 \theta}(r, \phi-\pi)=u_{2 \theta}(r, \phi-\pi) \\
\sigma_{1 \theta \theta}(r, \phi)=\sigma_{2 \theta \theta}(r, \phi) & \sigma_{3 \theta \theta}(r, \phi-\pi)=\sigma_{2 \theta \theta}(r, \phi-\pi) \\
\sigma_{1 r \theta}(r, \phi)=\sigma_{2 r \theta}(r, \phi) & \sigma_{3 r \theta}(r, \phi-r)=\sigma_{2 r \theta}(r, \phi-r)
\end{array}
$$

The corresponding stress singularity exponents can be determined from Eigen values as:

$$
\mathrm{p}_{1}=1-\lambda 1 \quad \text { and } \quad \mathrm{p}_{2}=1-\lambda 2
$$

The general expression describing the stress field around the crack tip touching the interface between two materials is given by the following equations (generally, two stress singularity exponents $\mathrm{p}_{1}$ and $\mathrm{p}_{2}$ exist): [17].

$$
\sigma_{i j}=\frac{H_{1}}{\sqrt{2 \pi}} \cdot r^{p_{1}} f_{1 i j}\left(p_{1}, \theta, \alpha, \beta, \phi\right)+\frac{H_{2}}{\sqrt{2 \pi}} r^{-p_{2}} f_{2 i j}\left(p_{2}, \theta, \alpha, \beta, \phi\right)
$$

where $\mathrm{H} 1$ [Mpa.m $\left.{ }^{\mathrm{P} 1}\right]$ and $\mathrm{H} 2\left[\mathrm{Mpa}^{\mathrm{P} 2}\right.$ ] are generalized stress intensity factors, $\mathrm{f}_{1 \mathrm{ij}}$ $\left(\mathrm{p}_{1}, \theta, \alpha, \beta, \varphi\right)$ and $\mathrm{f}_{2 \mathrm{ij}}\left(\mathrm{p}_{2}, \theta, \alpha, \beta, \varphi\right)$ are known functions, $(\mathrm{r}, \theta)$ are polar coordinates with their beginning at the crack tip and $\mathrm{p}_{1}$ and $\mathrm{p}_{2}$ are stress singularity exponents. $\alpha, \beta$ are Dundurs parameters [18] and represent elastic constants of a bimaterial body:

$\alpha=\frac{\mu_{2}\left(k_{1}+1\right)-\mu_{1}\left(\kappa_{2}+1\right)}{\mu_{2}\left(\kappa_{1}+1\right)+\mu_{1}\left(\kappa_{2}+1\right)} \quad \beta=\frac{\mu_{2}\left(k_{1}-1\right)-\mu_{1}\left(\kappa_{2}-1\right)}{\mu_{2}\left(\kappa_{1}+1\right)+\mu_{1}\left(\kappa_{2}+1\right)}$

where the shear modulus $\mu=E_{m} / 2\left(1+v_{m}\right)$ ( $E_{m}$ is Young's modulus) and parameters $\kappa_{m}=\frac{3-v_{m}}{1+v_{m}}$ for the case of plane stress or $\mathrm{m} \kappa_{\mathrm{m}}=3-4 v_{m}$ for plane strain $(\mathrm{m}=1,2$ corresponds to the number of the material). 
Note that values $\mathrm{H}_{1}$ and $\mathrm{H}_{2}$ do not mark the appurtenance to the normal or the shear mode of loading, but the values include both modes of loading. For a crack touching the interface the general form of the stress components is given by Eqs. (5).

$$
\begin{aligned}
& \sigma_{r r}{ }^{(j)}=-\sum_{i=1}^{2} \frac{H}{\sqrt{2 \pi}} r^{\lambda_{i-1}} \lambda_{i}\left[\begin{array}{l}
a_{i}{ }^{(j)}\left(\lambda_{i}+1\right) \sin \left(\lambda_{i}+1\right) \theta+b_{i}^{(j)}\left(\lambda_{i}+1\right) \cos \left(\lambda_{i}+1\right) \theta+ \\
c_{i}{ }^{(j)}\left(\lambda_{i}-3\right) \sin \left(\lambda_{i}-1\right) \theta+d_{i}{ }^{(j)}\left(\lambda_{i}-3\right) \cos \left(\lambda_{1}-1\right) \theta
\end{array}\right] \\
& \sigma_{\theta \theta}{ }^{(j)}=-\sum_{i=1}^{2} \frac{H}{\sqrt{2 \pi}} r^{\lambda_{i-1}} \lambda_{i}\left(\lambda_{i}+1\right)\left[\begin{array}{l}
a_{i}^{(j)} \sin \left(\lambda_{i}+1\right) \theta+b_{i}{ }^{(j)} \cos \left(\lambda_{i}+1\right) \theta+ \\
c_{i}{ }^{(j)} \sin \left(\lambda_{i}-1\right) \theta+d_{i}{ }^{(j)} \cos \left(\lambda_{1}-1\right) \theta
\end{array}\right] \\
& \sigma_{r \theta}{ }^{(j)}=-\sum_{i=1}^{2} \frac{H}{\sqrt{2 \pi}} r^{\lambda_{i-1}} \lambda_{i}\left[\begin{array}{l}
a_{i}{ }^{(j)}\left(\lambda_{i}+1\right) \cos \left(\lambda_{i}+1\right) \theta-b_{i}{ }^{(j)}\left(\lambda_{i}+1\right) \sin \left(\lambda_{i}+1\right) \theta+ \\
c_{i}{ }^{(j)}\left(\lambda_{i}-1\right) \cos \left(\lambda_{i}-1\right) \theta+d_{i}{ }^{(j)}\left(\lambda_{i}-1\right) \sin \left(\lambda_{1}-1\right) \theta
\end{array}\right]
\end{aligned}
$$

The subscript $i=1,2$ means the number of singularity within the interval $(0 ; 1)$.

The superscript $j=1,2,3$ marks the number of regions. The constants $a_{i}{ }^{(j)}, b_{i}{ }^{(j)}, c_{i}{ }^{(j)}$ and $d_{i}{ }^{(j)}$ represent the known eigenvector $\{x\},[17,18]$.

\section{Stress Intensity Factor in Practice}

Engineers are interested in the maximum stress near the crack tip and whether it exceeds the fracture toughness. Thus, the stress intensity factor $\mathrm{K}$ is commonly expressed in terms of the applied stresses ${ }^{\sigma}$ at $r \rightarrow 0$ and $\theta=0$. For example, for a through crack in an infinite plate under uniform tension ${ }^{\sigma}$, the stress intensity factor is $K_{I}=\sigma \sqrt{\pi \alpha}$ where a is one half of the width of the through crack. The dimension of $\mathrm{K}$ is:

$$
\operatorname{DIM}[K]=\frac{F}{L^{2}} \sqrt{L}=F L^{-3 / 2}=\text { Stress. } \sqrt{\text { Length }}
$$

Fig. 5 Stress Intensity Factor $K_{I}[19]$

In the last few decades, many closed-form solutions of the stress intensity factor $\mathrm{K}$ for simple configurations were derived.

\section{Results and Discussion}

Numerical results are presented for isotropic and orthotropic rectangular plates with a many values of the correction factor for the mode I stress intensity factor for a double edge cracked tension having normalized crack lengths of $\lambda=2 \mathrm{a} / \mathrm{h}=0.1$ to 0.3 . The material properties of different used materials were shown in Table (1). Where; E, G and $\mu$ represent modulus of elasticity, modulus of rigidity and Poisson's ratio respectively and fig. (3) provides the boundary conditions. Stresses are obtained for uniformly tensile loads $T=(5 \mathrm{~N})$ for all cases. The stresses in all directions for full plate made of different materials are discussed as following:

In fig $\mathrm{g}_{\mathrm{s}}(6,8,10,12)$ using isotropic plate the value of $\boldsymbol{\sigma}_{\mathbf{x}}$ stress begin from (52.5) $\mathrm{Pa}$ at ( $\lambda=0.1)$ and reach to $(92.7) \mathrm{Pa}$ at $(\lambda=0.3)$ but (under the same conditions) in the case of using orthotropic will be (53.5) $\mathrm{Pa}$ at $(\lambda=0.1)$ and reach to (89.6) $\mathrm{Pa}$ at $(\lambda=0.3)$. In figs. $(14,16,18,20)$, using isotropic plate the value of $\boldsymbol{\sigma}_{\mathbf{y}}$ stress begin from (24.8) $\mathrm{Pa}$ at $(\lambda=0.1)$ and 
reach to (47.8) $\mathrm{Pa}$ at $(\lambda=0.3)$ but ( under the same conditions) in the case of using orthotropic will be (31.5) $\mathrm{Pa}$ at $(\lambda=0.1)$ and reach to $(34.5) \mathrm{Pa}$ at $(\lambda=0.3)$. In fig $\mathrm{s}_{\mathrm{s}}(22,23,24,25)$ using isotropic plate the value of Von Mises stress begins from (64.4) $\mathrm{Pa}$ at $(\lambda=0.1)$ and up to (81.8) $\mathrm{Pa}$ at $(\lambda=0.3)$ but (under the same conditions) in the case of the using orthotropic will be (63.2) $\mathrm{Pa}$ at $(\lambda=0.1)$ and up to $(79.5) \mathrm{Pa}$ at $(\lambda=0.3)$. In fig $\mathrm{s}_{\mathrm{s}}(26,27,28,29)$ using isotropic plate the value of $\sigma_{\mathbf{x y}}$ stress begins from (4.3) Pa at $(\lambda=0.1)$ and up to (10.8) $\mathrm{Pa}$ at $(\lambda=0.3)$ but (under the same conditions) in the case of using orthotropic will be (2.9) $\mathrm{Pa}$ at $(\lambda=0.1)$ and reach to (7.8) $\mathrm{Pa}$ at $(\lambda=0.3)$. Fig. (30) shows the following observations of these results, it can be noticed that the variation of $\boldsymbol{\sigma}_{\mathbf{x}}$ with respect to $(\lambda)$ is increased (in same path) from (52.5) to (92.7) $\mathrm{pa}$ in the case of isotropic material and from (53.5) to (89.6) $\mathrm{Pa}$ for orthotropic material with the increase of $(\lambda)$ from 0.1 to 0.3 . Fig. (31) shows the following observations from these results, it can be noticed that the variation of $\boldsymbol{\sigma}_{\mathbf{y}}$ with respect to $(\lambda)$ is increased from (24.8) and (19.2) Pa to (42.5) and (33.1) Pa for isotropic and orthotropic materials respectively at $(\lambda=0.2)$ then it is increased to reach a max. value (47.8) Pa for isotropic but remained approximately at (34.5) Pa for orthotropic material with increase of $(\lambda)$ from 0.2 to 0.3 . Fig. (32) shows the following observations from these results, it can be noticed that the variation of $\boldsymbol{\sigma}_{\mathrm{von}}$ with respect to $(\lambda)$ is at first about (47.8) $\mathrm{Pa}$ for isotropic and (48.3) Pa for orthotropic, then it is increased to (46.9) and (55.6) $\mathrm{Pa}$ for isotropic and orthotropic respectively at $(\lambda=0.2)$ and finally it is increase to reach a maximum values(81.8) Pa for isotropic and(79.5) Pa for orthotropic with increase of $(\lambda)$ from 0.2 to 0.3 . Fig. (33) shows the following observations from these results, it can be noticed that the variation of $\boldsymbol{\sigma}_{\mathbf{x y}}$ with respect to $(\lambda)$ is increase (in same path) from (2.6) to (10.8) $\mathrm{Pa}$ in the case of isotropic material and from (1.8) to (7.8) Pa for orthotropic material with increase of $(\lambda)$ from 0.1 to 0.3 .

Not that fig s. $(7,9,11,13,15,17,19,21)$ showing the enlarge view of fig. $(6,8,10,12,14$, $16,18,20)$ respectively.

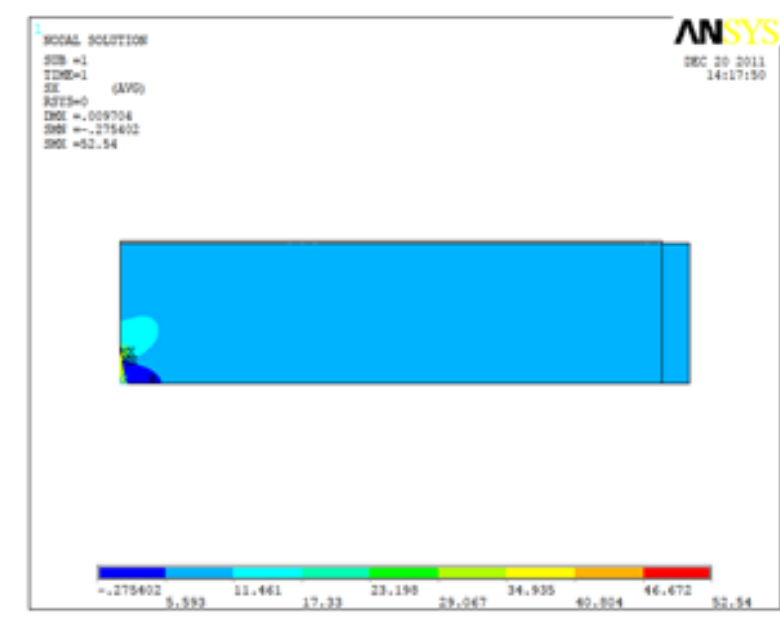

Fig. 6 Contour of the $\mathrm{x}$-component $\left(\boldsymbol{\sigma}_{\mathbf{x}}\right)$ of stress at $(\lambda=0.1)$ in the center-cracked tension plate (Isotropic).

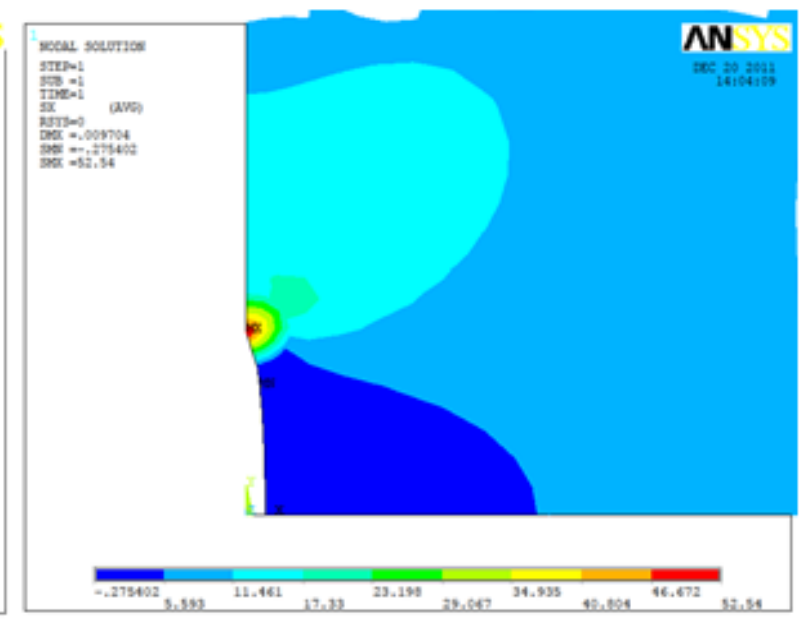

Fig. 7 Enlarged view of the longitudinal $\operatorname{stress}\left(\boldsymbol{\sigma}_{\mathbf{x}}\right)$ distribution around the crack tip(Isotropic). 


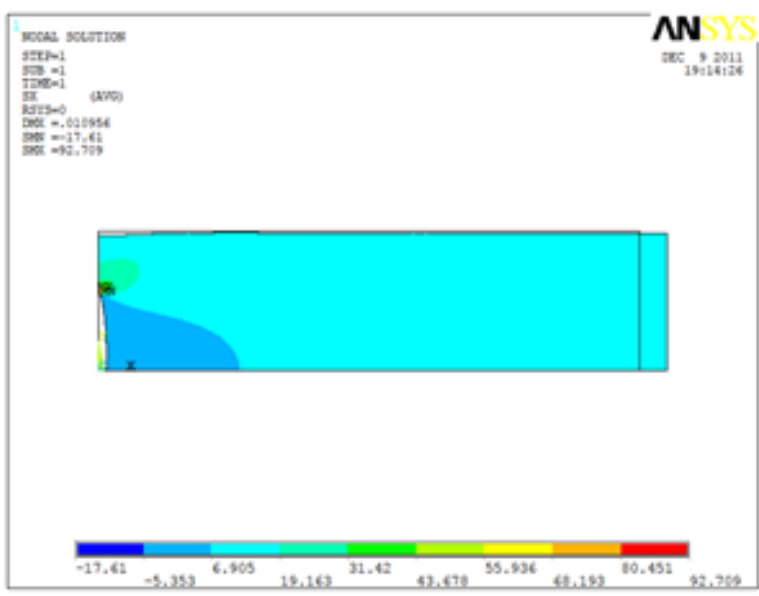

Fig. 8 Contour of the $\mathrm{x}$-component $\left(\boldsymbol{\sigma}_{\mathbf{x}}\right)$ of stress at $(\lambda=0.3)$ in the center-cracked tension plate (Isotropic).

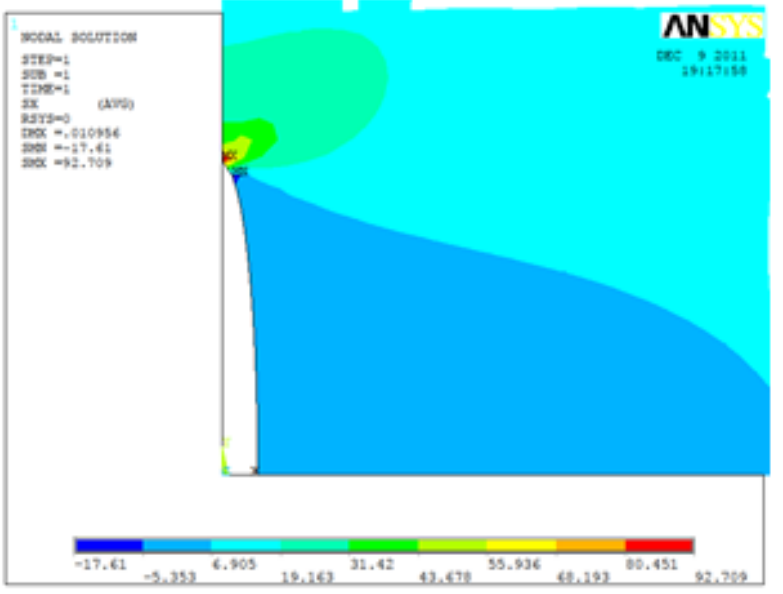

Fig. 9 Enlarged view of the longitudinal stress $\left(\boldsymbol{\sigma}_{\mathbf{x}}\right)$ distribution around the crack tip(Isotropic).

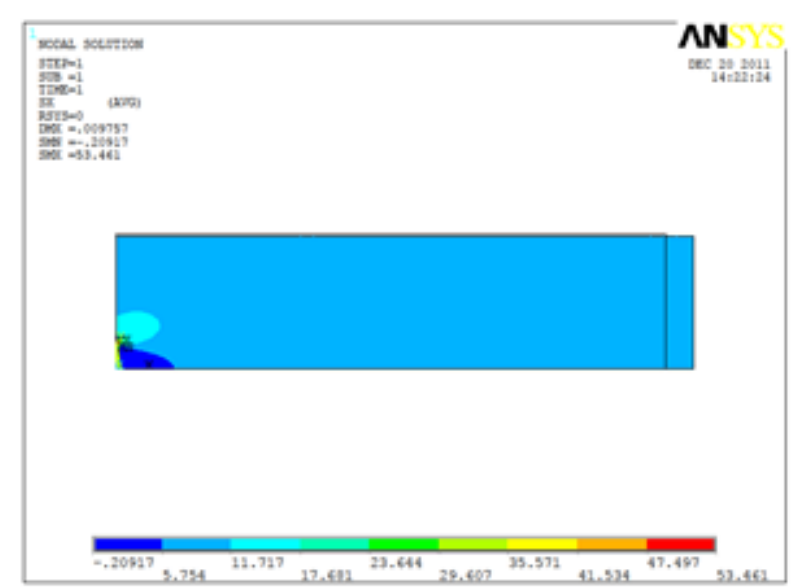

Fig. 10 Contour of the $\mathrm{x}$-component $\left(\boldsymbol{\sigma}_{\mathbf{x}}\right)$ of stress at $(\lambda=0.1)$ in the center-cracked tension plate(Orthotropic).

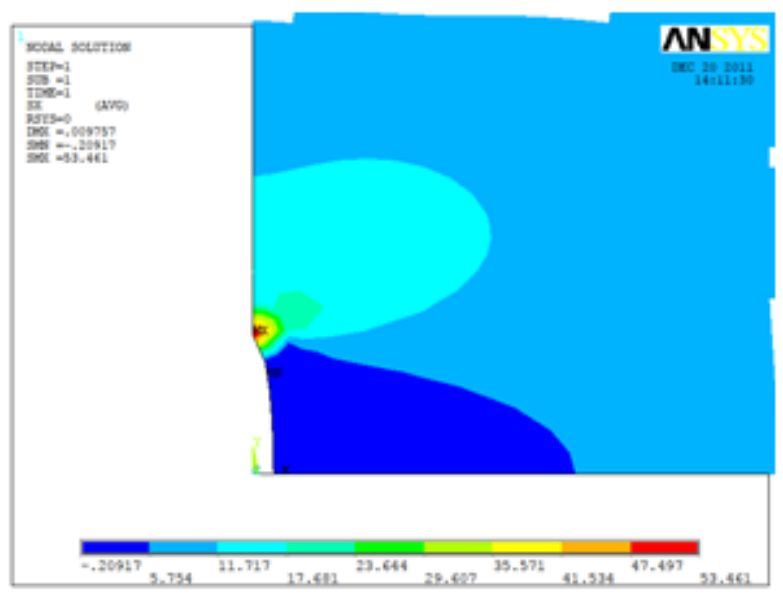

Fig. 11 Enlarged view of the longitudinal stress . $\left(\boldsymbol{\sigma}_{\mathbf{x}}\right)$ distribution around the crack tip(Orthotropic).

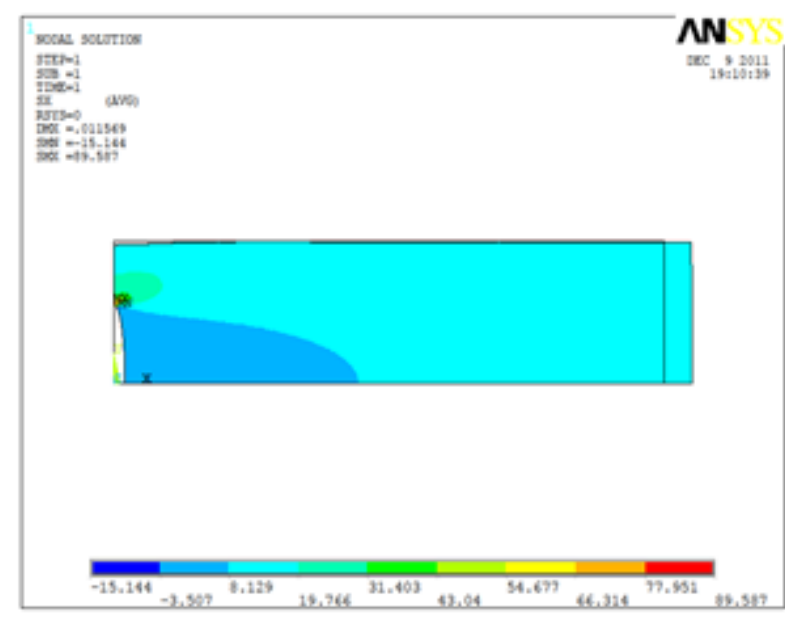

Fig. 12 Contour of the $\mathrm{x}$-component $\left(\boldsymbol{\sigma}_{\mathbf{x}}\right)$ of stress at $(\lambda=0.3)$ in the center-cracked tension plate(Orthotropic).

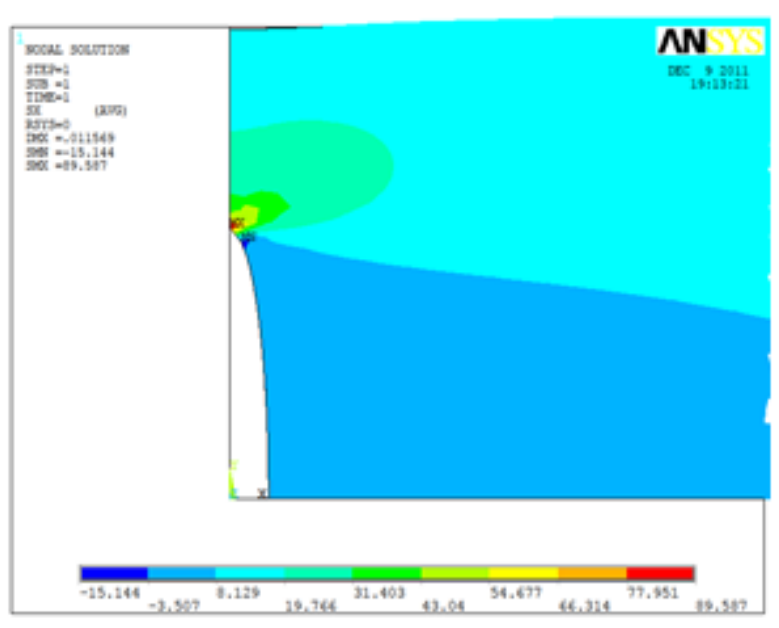

Fig. 13 Enlarged view of the longitudinal stress 

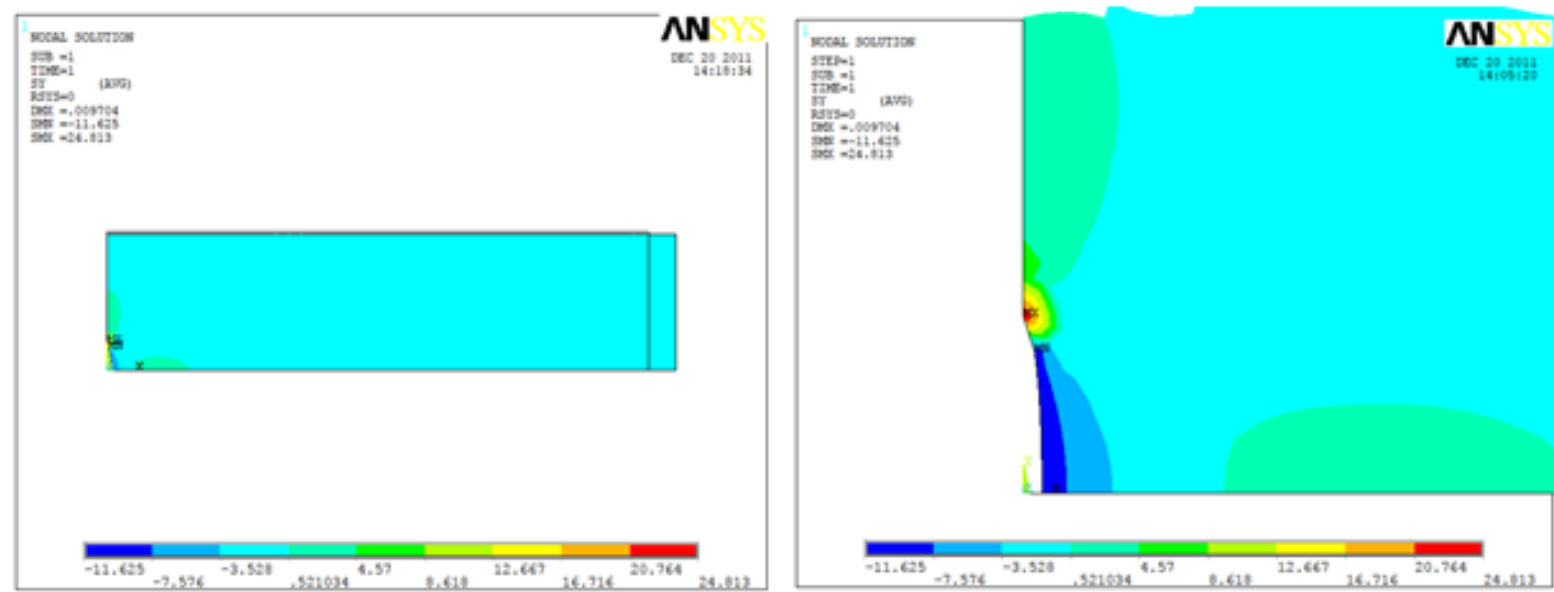

Fig.14 Contour of the y-component $\left(\boldsymbol{\sigma}_{\mathbf{y}}\right)$ of stress at

Fig. 15 Enlarged view of the longitudinal stress $(\lambda=0.1)$ in the center-cracked tension plate (Isotropic).

$\left(\boldsymbol{\sigma}_{\mathbf{y}}\right)$ distribution around the crack tip(Isotropic).
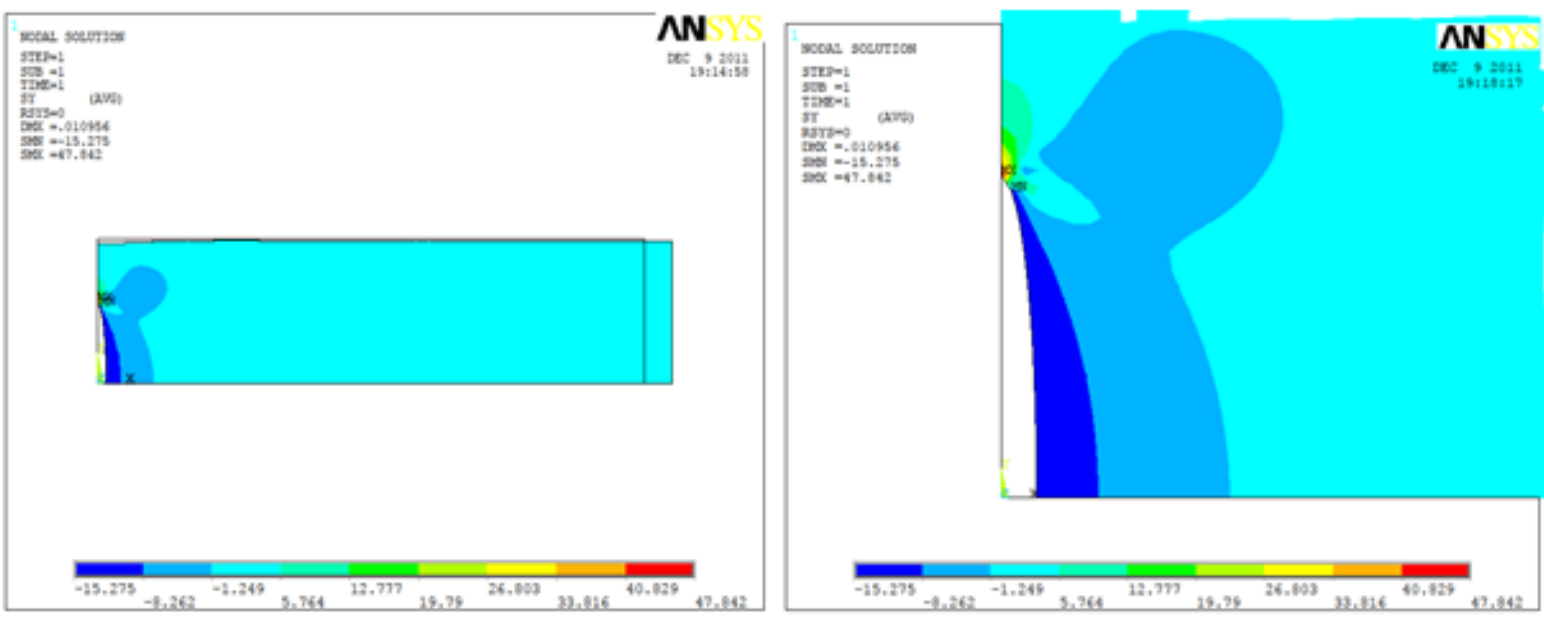

Fig. 16 Contour of the y-component $\left(\boldsymbol{\sigma}_{\mathbf{y}}\right)$ of stress at $(\lambda=0.3)$ in the center-cracked tension plate (Isotropic).

Fig. 17 Enlarged view of the longitudinal stress

$\left(\boldsymbol{\sigma}_{\mathbf{y}}\right)$ distribution around the crack tip(Isotropic).
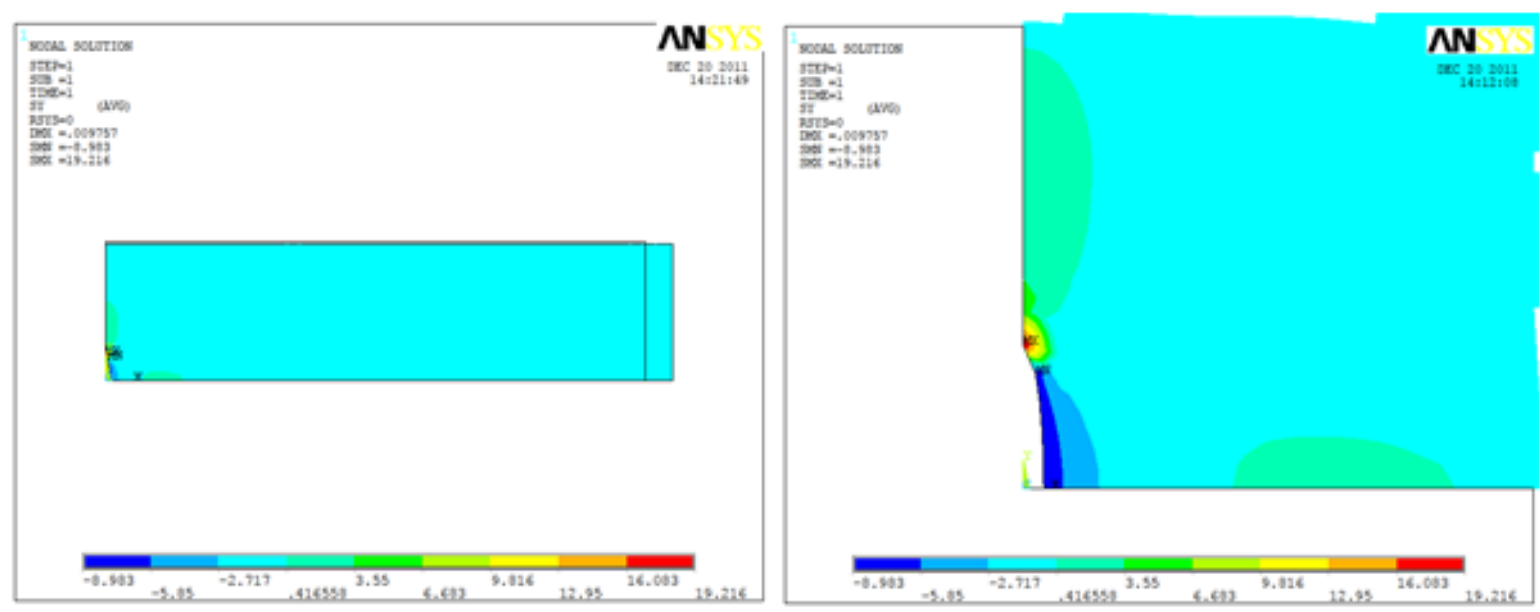

Fig. 18 Contour of the $y$-component $\left(\boldsymbol{\sigma}_{\mathbf{y}}\right)$ of stress at

Fig. 19 Enlarged view of the longitudinal stress $\left(\boldsymbol{\sigma}_{\mathbf{y}}\right)$ $(\lambda=0.1)$ in the center-cracked tension plate(Orthotropic). distribution around the crack tip(Orthotropic). 


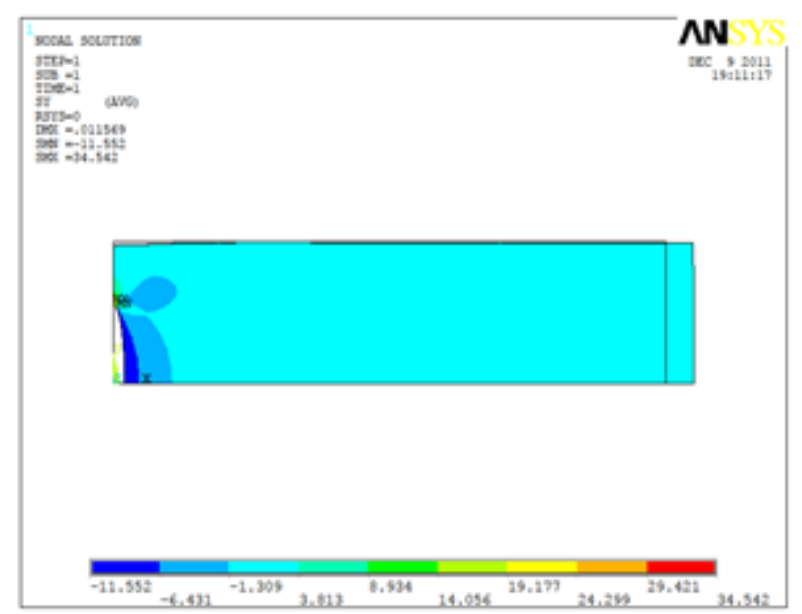

Fig. 20 Contour of the y-component $\left(\boldsymbol{\sigma}_{\mathbf{y}}\right)$ of stress at $(\lambda=0.3)$ in the center-cracked tension plate(Orthotropic).

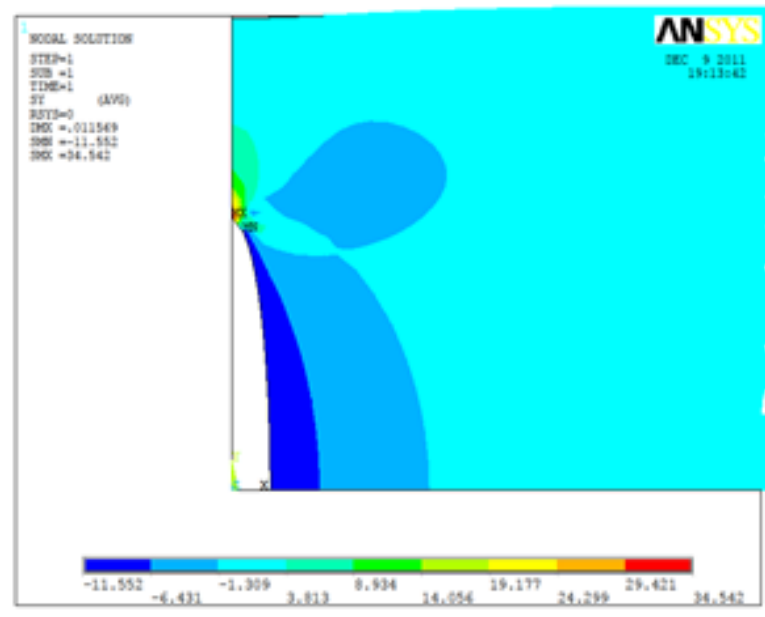

Fig. 21 Enlarged view of the longitudinal stress $\left(\boldsymbol{\sigma}_{\mathbf{y}}\right)$ distribution around the crack tip(Orthotropic).

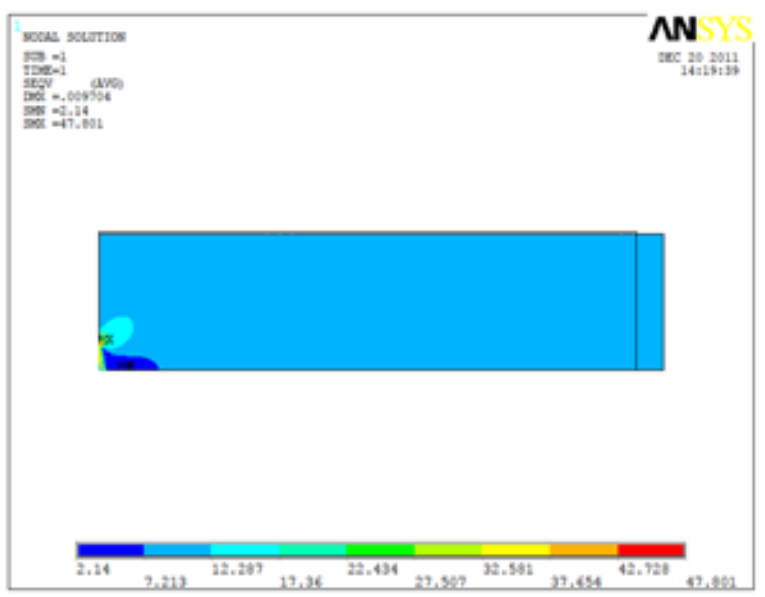

Fig. 22 Contour of the stress distribution $\left(\boldsymbol{\sigma}_{\mathrm{von}}\right)$ of stress at $(\lambda=0.1)$ in the center-cracked tension plate(Isotropic).

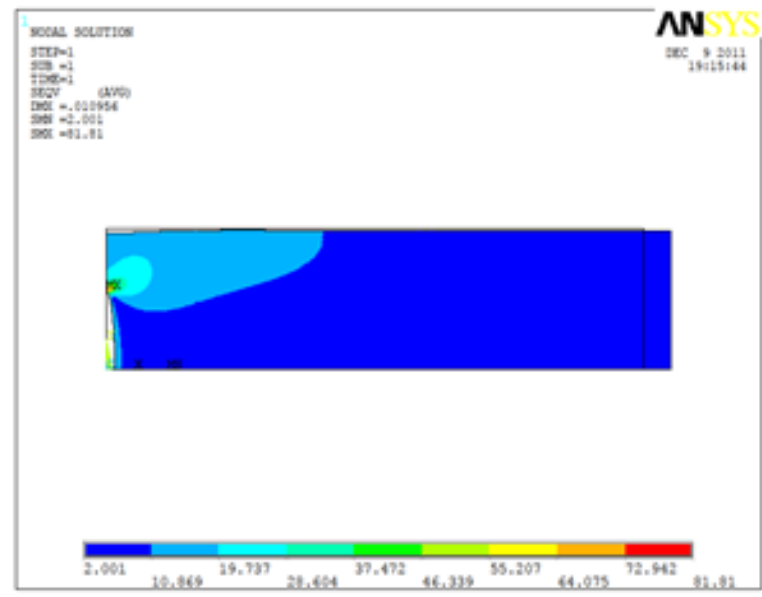

Fig. 23 Contour of the stress distribution $\left(\boldsymbol{\sigma}_{\mathrm{von}}\right)$ of stress at $(\lambda=0.3)$ in the center-cracked tension plate(Isotropic).

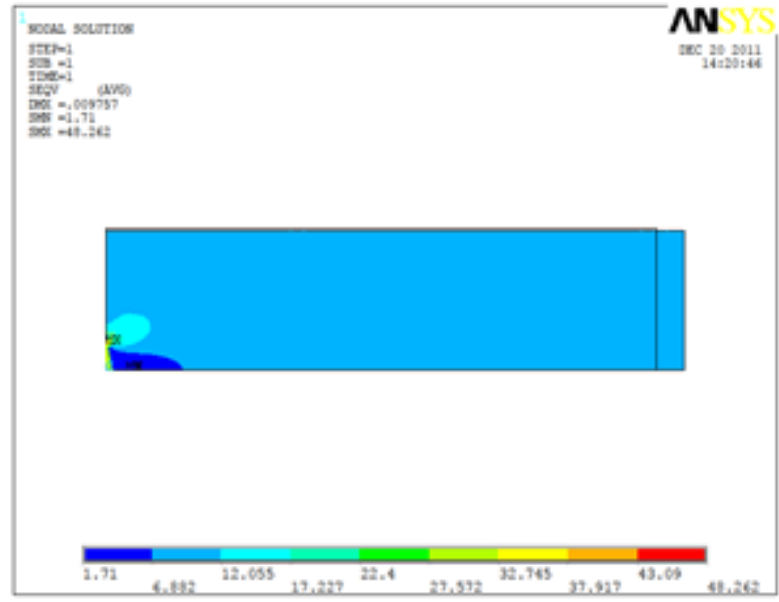

Fig. 24 Contour of the stress distribution $\left(\boldsymbol{\sigma}_{\mathrm{von}}\right)$ of stress at $(\lambda=0.1)$ in the center-cracked tension plate(Orthotropic).

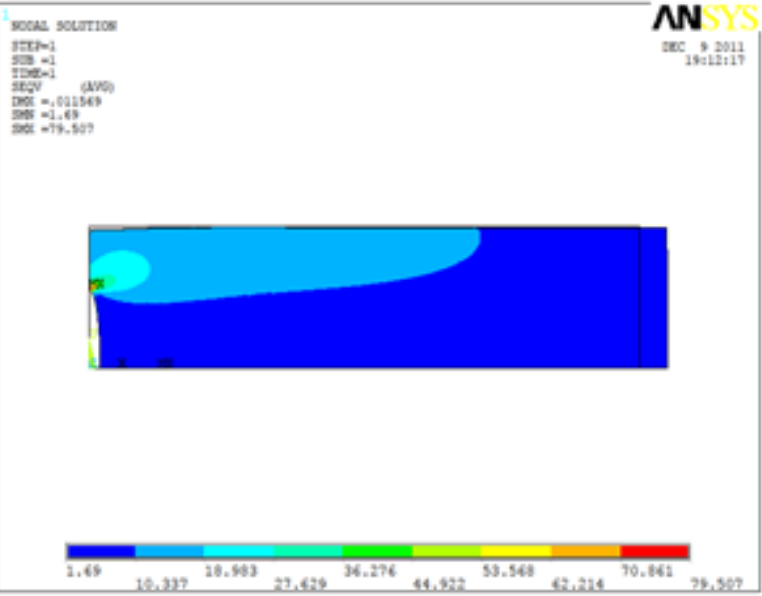

Fig. 25 Contour of the stress distribution $\left(\boldsymbol{\sigma}_{\mathrm{von}}\right)$ of stress at $(\lambda=0.3)$ in the center-cracked tension plate(Orthotropic). 

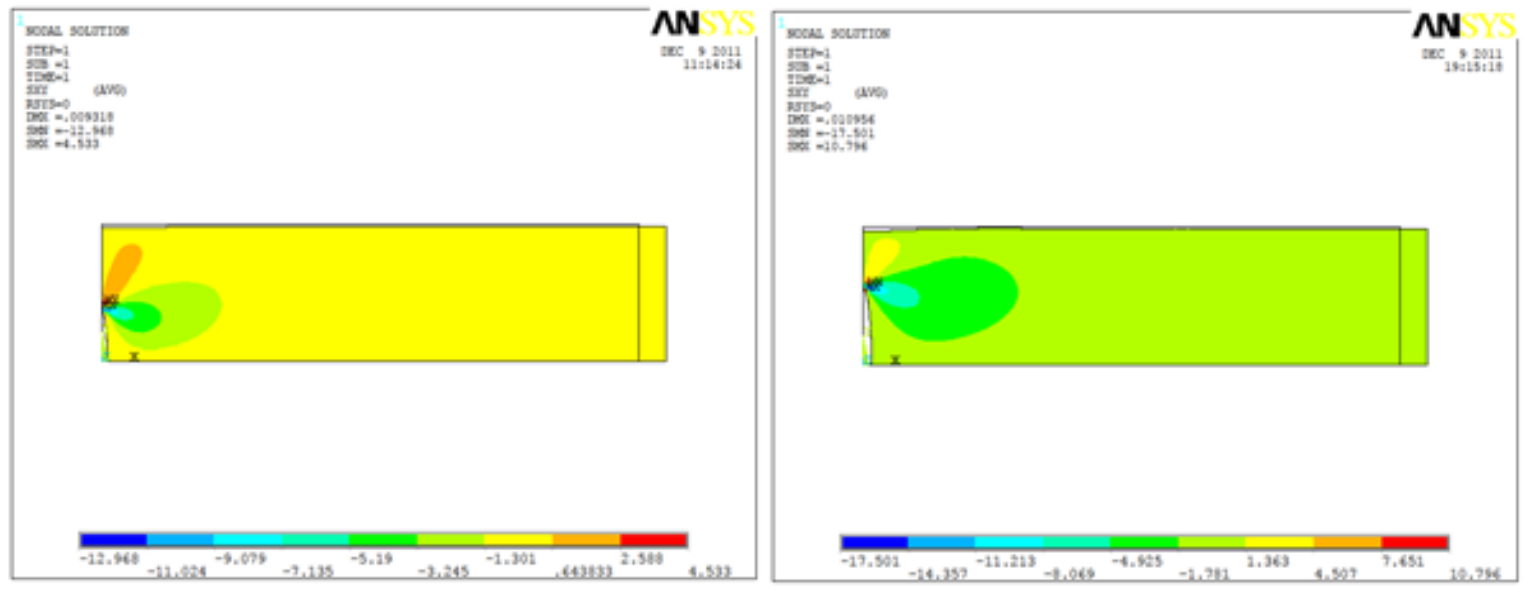

Fig. 26 Contour of the xy-plane $\left(\boldsymbol{\sigma}_{\mathbf{x y}}\right)$ of stress at $(\lambda=0.1)$ in the center-cracked tension plate(Isotropic).

Fig. 27 Contour of the xy-plane $\left(\boldsymbol{\sigma}_{\mathbf{x y}}\right)$ of stress at $(\lambda=0.3)$ in the center-cracked tension plate(Isotropic).
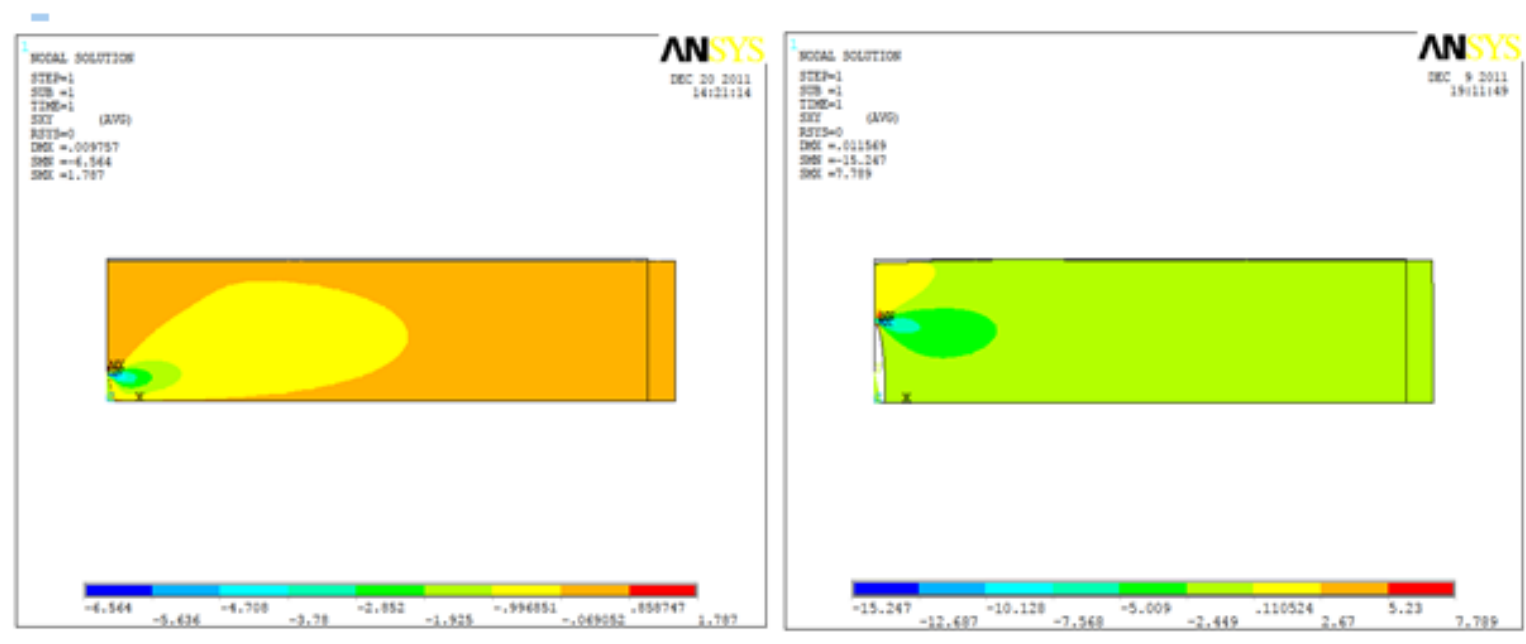

Fig. 28 Contour of the xy-plane $\left(\boldsymbol{\sigma}_{\mathbf{x y}}\right)$ of stress at $(\lambda=0.1)$ in the center-cracked tension plate(Orthotropic).

Fig.29 Contour of the xy-plane $\left(\boldsymbol{\sigma}_{\mathbf{x y}}\right)$ of stress $(\lambda=0.3)$ at in the center-cracked tension plate(Orthotropic).

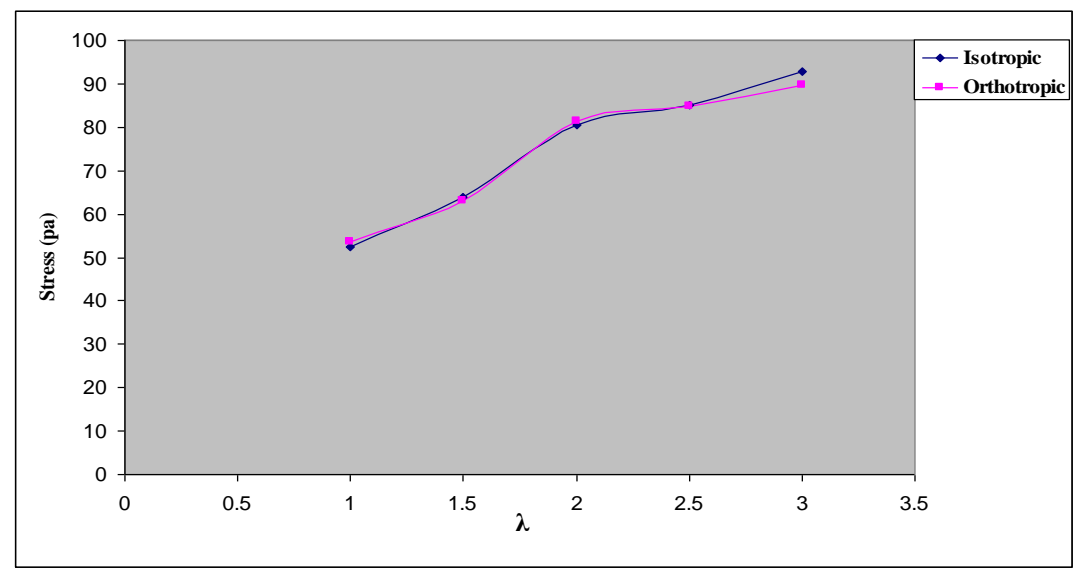

Fig. 30 Effect of correction factor $F(\lambda)$ on $\left(\boldsymbol{\sigma}_{\mathbf{x}}\right)$ in plates of an isotropic and orthotropic materials. 


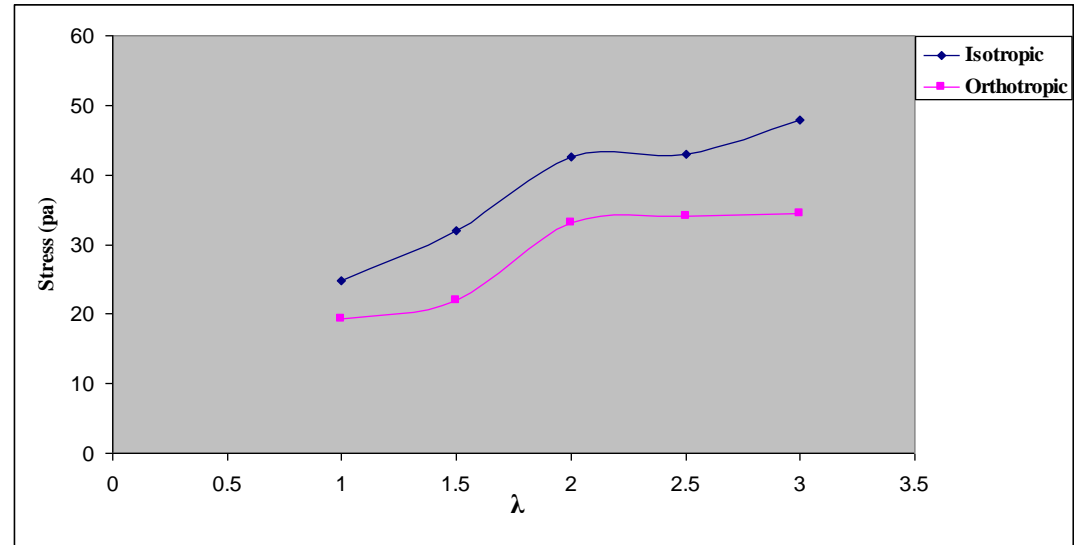

Fig. 31 Effect of correction factor $F(\lambda)$ on $\left(\boldsymbol{\sigma}_{\mathbf{y}}\right)$ in plates of an isotropic and orthotropic materials.

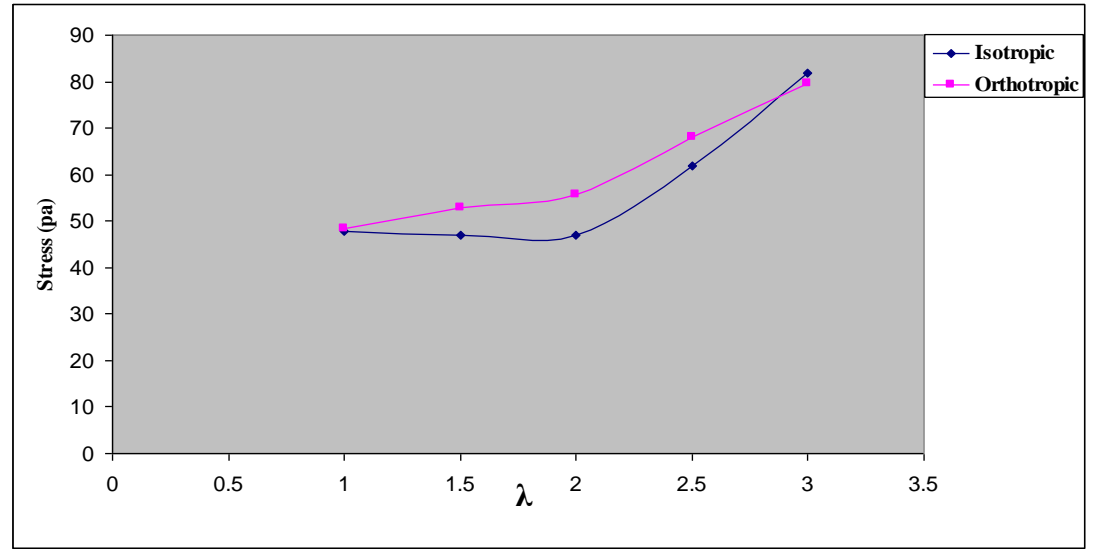

Fig. 32 Effect of correction factor $F(\lambda)$ on $\left(\boldsymbol{\sigma}_{\mathbf{v o n}}\right)$ in plates of an isotropic and orthotropic materials.

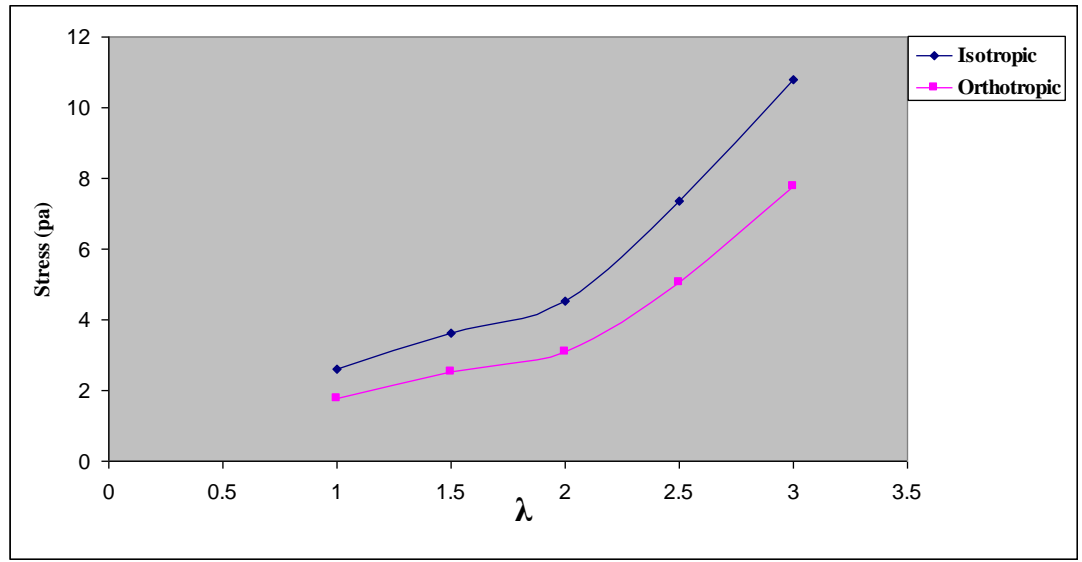

Fig. 33 Effect of correction factor $F(\lambda)$ on $\left(\boldsymbol{\sigma}_{\mathbf{x y}}\right)$ in plates of an isotropic and orthotropic materials.

Table (2): Results of all cases with material properties which used in the analysis.

\begin{tabular}{|c|c|c|c|c|}
\hline \multirow{2}{*}{ Stresses } & \multicolumn{2}{|c|}{ Isotropic } & \multicolumn{2}{c|}{ Orthotropic } \\
\cline { 2 - 5 } & $\boldsymbol{\lambda}=\mathbf{0 . 1}$ & $\boldsymbol{\lambda}=\mathbf{0 . 3}$ & $\boldsymbol{\lambda}=\mathbf{0 . 1}$ & $\boldsymbol{\lambda}=\mathbf{0 . 3}$ \\
\hline $\boldsymbol{\sigma}_{\mathbf{x}}$ & $52.5 \mathrm{~Pa}$ & $92.7 \mathrm{~Pa}$ & $53.5 \mathrm{~Pa}$ & $89.6 \mathrm{~Pa}$ \\
\hline $\boldsymbol{\sigma}_{\mathbf{y}}$ & $24.8 \mathrm{~Pa}$ & $47.8 \mathrm{~Pa}$ & $19.2 \mathrm{~Pa}$ & $34.5 \mathrm{~Pa}$ \\
\hline $\boldsymbol{\sigma}_{\mathbf{v o n}}$ & $47.8 \mathrm{~Pa}$ & $81.8 \mathrm{~Pa}$ & $48.3 \mathrm{~Pa}$ & $79.5 \mathrm{~Pa}$ \\
\hline $\boldsymbol{\sigma}_{\mathbf{x y}}$ & $2.6 \mathrm{~Pa}$ & $10.8 \mathrm{~Pa}$ & $1.8 \mathrm{~Pa}$ & $7.8 \mathrm{~Pa}$ \\
\hline
\end{tabular}




\section{Conclusions}

Two models of cracks were prepared using finite element (ANSYS package) which simulate in order to help us for understanding the stress concentration in any part of the plates, and results were compared. However, we can conclude the following:

1- The variation of the stresses $\left(\boldsymbol{\sigma}_{\mathbf{x}}\right)$ with respect to $(\lambda)$ was clearly observed in orthotropic and isotropic plates and were approximately equal for the two plates. The variation of the stresses $\left(\sigma_{\mathbf{y}}\right)$ with respect to $(\lambda)$ observed was found to be less in orthotropic plate as compared to isotropic plates.

2- For isotropic plate the variation of the $\left(\boldsymbol{\sigma}_{\mathrm{von}}\right)$ with respect to $(\lambda)$ is approximately remained constant from $(\lambda=0.1$ to 0.2$)$. On the other hand only the variation of the $\left(\boldsymbol{\sigma}_{\mathrm{von})}\right.$ with respect to $(\lambda)$ was observed large in orthotropic as compared to isotropic plates especially when $(\lambda)$ was reached $(0.2)$.

3- The maximum shear stress $\left(\boldsymbol{\sigma}_{\mathbf{x y}}\right)$ with respect to $(\lambda)$ for the two materials which occurred in the XY plane was varied significant. This variation was observed more in orthotropic plates comparing to isotropic plates and the two curves were moving approximately at the same path.

4- The variation of all stresses with respect to $(\lambda)$; doesn't highly depended on the elastic constants and not functional of the materials, this is because of the two dimensional analysis 2- D that used for all materials, Hence the stresses SCF for $\left(\boldsymbol{\sigma}_{\mathbf{x}}\right)$ and $\left(\boldsymbol{\sigma}_{\mathbf{y}}\right)$ playing an important role in the design of plates.

\section{References}

1. Cracked Rotors " Survey on Static and Dynamic Behaviour Including Modelling and Diagnosis". Library of Congress Control Number: 2009941533 Springer-Verlag Berlin Heidelberg (2010).

2. Hall R. O., Rubber as an Engineering Material. International Journal of Materials in Engineering Applications 1; p, 295-302, (1979).

3. Samer Masoud Al- Said "Crack identification in a stepped beam carrying a rigid disk" Mech. Eng. Dept., Jordan University of Science and Technology, Journal of Sound and Vibration 300 (2007) 863-876, England (2006).

4. Massab` o, R., Brandinelli, L. and Cox, B.N. Mode I weight functions for an orthotropic double cantilever beam. International Journal of Engineering Science 41, 1497-1518. (2003).

5. Irwin GR. The crack extension force for a part through crack in a plate. J Appl Mech29:651-4; (1962).

6. Irwin GR. Encyclopedia of physics, vol. 6. Berlin: Springer; (1958).

7. Williams ML. On the stress distribution at the base of a stationary crack. J Appl Mech, 24:109-14; (1957). 
8. Sedov LI. A course in continuum mechanics, vol. 4. Groningen: Volters- Noordhoff; (1972).

9. Tada H, Paris PC, Irvin GR. The stress analysis of cracks handbook, 3rd ed.. Professional engineering publishing; (2000).

10. Duffield RC, Willens N., Parametric resonance of rectangular plates. J Appl Mech;39:217-26, (1972).

11. Liaw BM, Kamel M., "Stress intensity factors for cracks emanating from a curvilinear hole in an anisotropic plate under arbitrary loading." Engineering fracture mechanics;36: 669-681, (1990).

12. Kotlyarenko A. A T. A. Prach, V. V. Kharchenko, UDC 539.4 and A. Yu. Chirkov "Numerical simulation of stress- strain state near crack tip in a compact tensile specimen ", Strength of Materials, Vol. 41, No. 1, |(2009).

13. Yu S. R, Yan Z. G, Cao R. and Chen J. H "On the change of fracture mechanism with test temperature,” Eng. Fract. Mech., 73, 331-347 (2006).

14. Ostby E. C., Thaulow, and Z. L. Zhang, "Numerical simulations of specimen size and mismatch effects in ductile crack growth. I. Tearing resistance and crack growth paths," Eng. Fract. Mech., 74, 1770-1792 (2007).

15. Ostby E. C., Thaulow, and Z. L. Zhang, "Numerical simulations of specimen size and mismatch effects in ductile crack growth. II. Near-tip stress fields,” Eng. Fract. Mech., 74, 1793-1809 (2007).

16. Loehnert S., Belytschko T.,(Crack shielding and amplification due to multiple microcracks interacting with a macro crack). Int J Fract 145:1-8, (2007).

17. Fenner D. N., Stress singularities in composite materials with an arbitrarily oriented crack meeting an interface. International Journal of Fracture 12(5):705-721. (1976).

18. Dundurs J Effect of elastic constants on stress. In: A Composite Under Plane Deformation. Journal of Composite Materials 1:310-322. (1967).

19. Shah, S. P., S. E. Swartz, and C. Ouyang. 1995. Fracture mechanics of concrete. 10158-0012. New York: John Wiley \& Sons, Inc., 605 Third Avenue.

The work was carried out at the college of Engineering. University of Mosul 